\title{
Carbon and hydrogen isotopes fractionation of TSR-altered gas products of thermal simulation experiment
}

\author{
Q $\mathrm{LIU}^{1,2 *}, \mathrm{~W} \mathrm{PENG}^{2}, \mathrm{Q} \mathrm{MENG}^{2}, \mathrm{D} \mathrm{ZHU}^{2}, \mathrm{Z} \mathrm{JIN}{ }^{2}, \mathrm{X}$ \\ $\mathrm{WU}^{2}$ \\ ${ }^{1}$ State Key Laboratory of Shale Oil and Gas Enrichment \\ Mechanisms and Effective Development, SINOPEC, \\ Beijing 100083, China \\ 2 Petroleum Exploration \& Production Research Institute, \\ SINOPEC, Beijing 100083, China \\ (*correspondence: qyouliu@sohu.com)
}

Thermochemical sulfate reduction (TSR) in marine carbonate gas reservoirs can produce different carbon and hydrogen isotopic compositions from those of conventional gas reservoirs. This study aims to better understand how TSR can affect geochemical and isotopic compositions of gas reservoirs. Laboratory simulation of TSR was conducted with crude oil in the presence of $\mathrm{MgSO}_{4}$ at temperatures of $350^{\circ} \mathrm{C}$, $360^{\circ} \mathrm{C}$, and $370^{\circ} \mathrm{C}$ for different durations of $4 \sim 219 \mathrm{~h}$ in a closed system. Results show that isotope compositions of alkane gas resulted from the TSR became heavier with increasing carbon number, i.e., $\delta^{13} \mathrm{C}_{1}<\delta^{13} \mathrm{C}_{2}<\delta^{13} \mathrm{C}_{3}$ and $\delta^{2} \mathrm{H}$ $\mathrm{C}_{1}<\delta^{2} \mathrm{H}-\mathrm{C}_{2}<\delta^{2} \mathrm{H}-\mathrm{C}_{3}$. However, at the same temperature, $\delta^{13} \mathrm{C}_{1}$ decreased at first and then became larger with increasing heating time within a certain range. Compared with the $\delta^{13} \mathrm{C}_{1}$, $\delta^{13} \mathrm{C}_{2}$ and $\delta^{13} \mathrm{C}_{3}$ increased in a much wider range as heating continued. Specifically, the $\delta^{13} \mathrm{C}_{2}$ varied in a range slightly smaller than the $\delta^{13} \mathrm{C}_{3}$. The narrower variation range of $\delta^{13} \mathrm{C}_{1}$ was because of rapid oxidation of hydrocarbons by TSR which produced $\mathrm{CH}_{4}$ with similar isotope compositions to the source material. Furthermore, carbon and hydrogen isotopes of alkane from TSR became larger with increasing gas souring index (GSI), i.e., $\mathrm{H}_{2} \mathrm{~S} /\left(\mathrm{H}_{2} \mathrm{~S}+\sum \mathrm{C}_{1-5}\right)$, and the $\mathrm{CH}_{4}$ had a smaller variation range than the $\mathrm{C}_{2} \mathrm{H}_{6} . \delta^{13} \mathrm{C}_{1}-\delta^{13} \mathrm{C}_{2}$ and $\delta^{2} \mathrm{H}$ $\mathrm{C}_{1}-\delta^{2} \mathrm{H}-\mathrm{C}_{2}$ normally decreased as oil underwent thermal cracking. However, they may show an increasing trend because TSR can reduce the variation range of isotopes of $\mathrm{CH}_{4}$. The isotope compositions of $\mathrm{C}_{2} \mathrm{H}_{6}$ were more heavily affected by thermal cracking before oxidization by TSR, which resulted in their short variation range. The rapid oxidation of hydrocarbons by TSR resulted in the series of $\delta^{13} \mathrm{C}_{1}>\delta^{13} \mathrm{C}_{2}$, which is similar to the isotopic composition of source materials. ${ }^{13} \mathrm{C}$ was gradually enriched in the residual heavy alkanes during the TSR process, which increased the $\delta^{13} \mathrm{C}_{2}$ value and changed the partially reversed isotope sequence to positive isotope sequence. 